\title{
An unusual case of ST-segment elevation myocardial infarction following a late bare-metal stent fracture in a native coronary artery: a case report
} Giovanni Minardi*1, Paolo G Pino ${ }^{1}$, Marco Stefano Nazzaro ${ }^{1}$, Herribert Pavaci², Martina Sordi², Cesare Greco ${ }^{2}$ and Carlo Gaudio ${ }^{2}$

\author{
Address: ${ }^{1}$ Department of Cardiology and Cardiovascular Surgery, Azienda Ospedaliera San Camillo-Forlanini, Rome, Italy and ${ }^{2}$ Department of \\ Heart and Great Vessels Attilio Reale, Second Division of Cardiology, "Sapienza", University of Rome, Rome, Italy \\ Email: Giovanni Minardi* - giovanni.minardi@libero.it; Paolo G Pino - ppino@scamilloforlanini.rm.it; \\ Marco Stefano Nazzaro - nazzaro@scamilloforlanini.rm.it; Herribert Pavaci - herrpav@ hotmail.com; Martina Sordi - martinasordi@yahoo.it; \\ Cesare Greco - cesare.greco@uniroma1.it; Carlo Gaudio - carlo.gaudio@tiscali.it \\ * Corresponding author
}

Published: 24 November 2009

Journal of Medical Case Reports 2009, 3:9296 doi:10.1 I86/1752-1947-3-9296
Received: 16 January 2009

Accepted: 24 November 2009

This article is available from: http://www.jmedicalcasereports.com/content/3/1/9296

(C) 2009 Minardi et al; licensee BioMed Central Ltd.

This is an Open Access article distributed under the terms of the Creative Commons Attribution License (http://creativecommons.org/licenses/by/2.0), which permits unrestricted use, distribution, and reproduction in any medium, provided the original work is properly cited.

\begin{abstract}
Introduction: A bare-metal stent fracture as a cause of acute coronary thrombosis and consequently of acute coronary syndrome is a rare clinical event that, to the best of our knowledge, has previously not been reported. A stent fracture is a rare complication arising from percutaneous coronary intervention.

Case presentation: We present, to the best of our knowledge, the first documented case of STsegment elevation myocardial infarction in a patient following a late bare-metal stent fracture and thrombosis in a native coronary artery. The patient, a $5 \mathrm{I}$-year-old Caucasian man, was treated successfully with primary percutaneous coronary intervention and a new stent implantation.

Conclusion: A coronary stent fracture is a rare complication that has been described in venous bypass grafts deploying either a drug-eluting stent or a bare-metal stent. Stent fractures rarely occur in coronary arteries. In light of the non-specific presentation of stent fracture, it is also an easily missed complication. Patients may present with a non-specific symptom of angina. The angina could either be stable or unstable as a result of restenosis or in-stent thrombosis, or both. Our case demonstrates the most severe consequences of a bare-metal stent fracture (sudden coronary thrombosis and subsequent myocardial infarction) in a native coronary artery. It was diagnosed angiographically and treated early and effectively.
\end{abstract}

\section{Introduction}

A bare-metal stent (BMS) fracture as a cause of acute coronary thrombosis and consequently of acute coronary syndrome (ACS) is a rare clinical event that, to the best of our knowledge, has previously not been reported.
A stent fracture is a rare complication of percutaneous coronary intervention (PCI). Drug-eluting stent (DES) fractures have an estimated incidence of $2.7 \%$ [1], and a BMS fracture in a saphenous vein graft has recently been described [2]. A late BMS fracture has also been reported, 
which was detected by 64-slice multidetector computed tomography (MDCT) [3].

\section{Case presentation}

A 51-year-old Caucasian man who smoked and was afflicted with dyslipidemia presented at our emergency department complaining of typical angina and shortness of breath. He had a family history of coronary artery disease. He had been successfully treated with coronary angioplasty 12 years before presentation. A 4.0/16.0 mm AVE Micro stent (AVE Inc., Santa Rosa, CA, USA) was deployed in the proximal left anterior descending artery (LAD). The stent was postdilated with a $4.0-\mathrm{mm}$ high dilatation force balloon (High Energy) at 14 atmospheres with good angiographic results. The patient was on therapy with aspirin, a statin, omega- 3 fatty acids and a $\beta$-blocker and had remained asymptomatic up to his admission.

An electrocardiogram showed a marked ST-segment elevation in leads V2-V6, I and aVL, suggesting an extended anterior acute myocardial infarction (Figure 1).

Emergency coronary angiography revealed total occlusion of the LAD with complete fracture of the mid portion of the stent (Figure 2 and Additional file 1). The circumflex artery had a non-critical plaque in the mid portion (50\%) and the right coronary artery was normal.

A percutaneous coronary intervention (PIC) was performed. After predilation, two Cypher stents (Cordis, Miami Lakes, FL, USA) $3.0 \times 33 \mathrm{~mm}$ in the middle part and $3.5 \times 8 \mathrm{~mm}$ proximally, respectively, were superposed on the previous stent in the fractured occlusion area. Subsequently, a third Cypher stent $2.75 \times 28 \mathrm{~mm}$ in the midLAD was deployed (Figure 3 and Additional file 2, Additional file 3 and Additional file 4).

Overlapped segments with extensor balloon $(3.5 \times 20$ $\mathrm{mm}$ ) postdilation were performed. The affected coronary

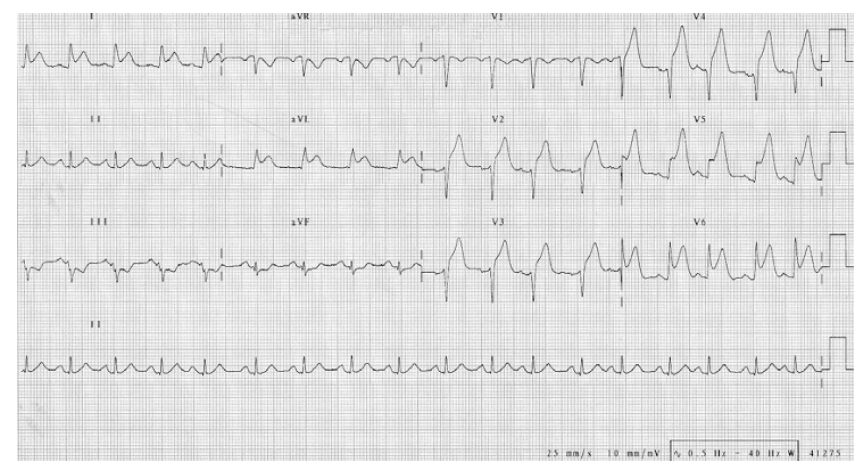

Figure I

A I 2-lead electrocardiography on admission indicating an anterior ST segment myocardial infarction.

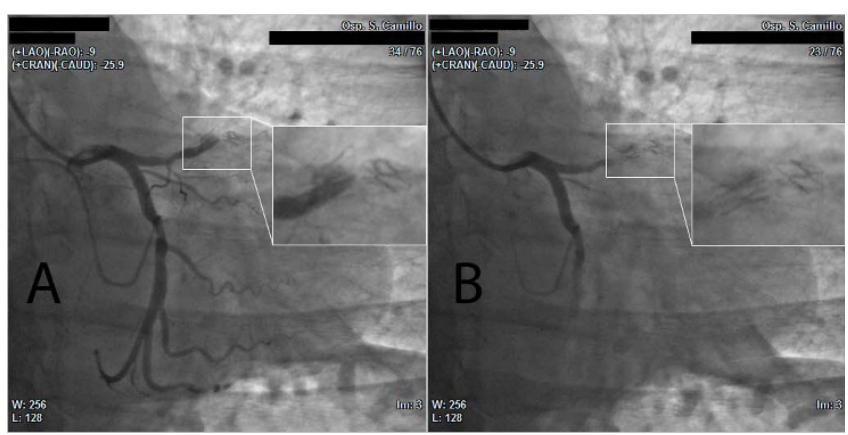

\section{Figure 2}

Coronary angiogram showing the proximal occlusion of the left anterior descending artery $(A)$ and stent fracture at a higher magnification (B).

artery was successfully reperfused (final TIMI 3 flow) (Figure 4 and Additional file 5). The peak troponin T level was $82.89 \mathrm{ng} / \mathrm{ml}$, myoglobin was greater than $1000 \mathrm{ng} / \mathrm{ml}$, and creatine kinase-MB level was $217.30 \mathrm{ng} / \mathrm{ml}$.

The patient was admitted to the coronary care unit and treated with double antiplatelet therapy (aspirin and clopidogrel) as well as a $\beta$-blocker, ACE-inhibitor, statin

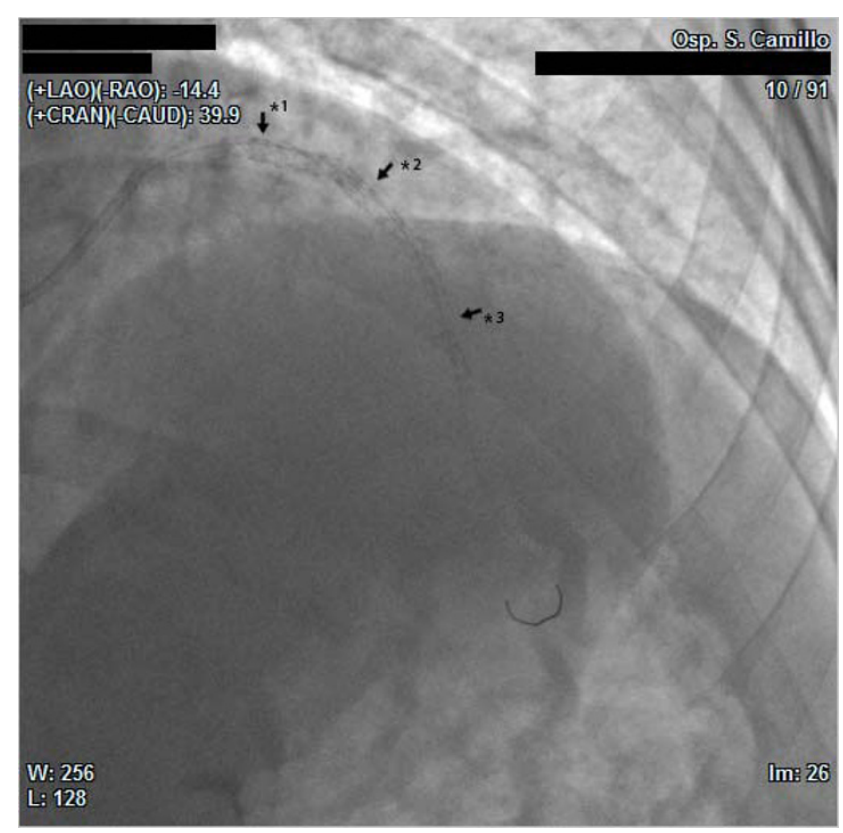

Figure 3

Final angiogram of the left anterior descending artery showing three Cypher stents placed in the fractured area: $(* 1)$ proximal $(3.5 \times 8 \mathrm{~mm}),(* 2)$ middle $(3.0 \times 33 \mathrm{~mm})$ and $(* 3)$ distal $(2.75 \times 28 \mathrm{~mm})$. 


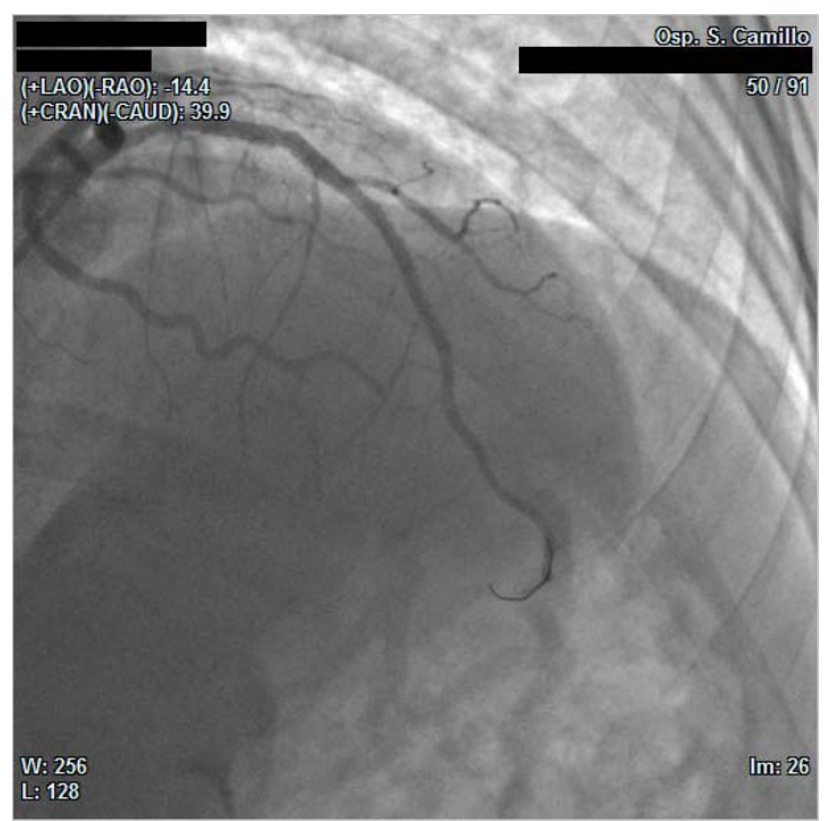

\section{Figure 4}

Final angiographic result: complete opacification of the left anterior descending artery.

and diuretic. The patient's later course was uneventful, as cardiac biomarkers normalized.

\section{Conclusion}

Stent fractures have been reported in vascular settings such as in the iliac artery [4] and the subclavian artery [5]. The mechanism of fracture has long been considered to be excessive mechanical stress due to extreme contraction and/or flexion of the vessel.

Coronary stent fracture is a rare complication and has been described in venous bypass grafts, deploying either DES or BMS [2]. In venous grafts, mechanical stress can be very high and may lead to coronary stent fracture. In addition, aggressive postdilation of a deployed stent may also lead to stent fracture.

Stent fractures occur very rarely in native coronary arteries. Around $2.7 \%$ of patients treated with DES have experienced a stent fracture $[1,6-9]$ and BMS can also break. Recently, BMS fractures have been detected in a 64-slice MDCT $[3,10]$. The potential risk of stent fracture must be considered when dealing with stent-to-vessel undersizing with subsequent aggressive postdilation. If the struts of the stent are compromised during this process, then the risk of stent fracture is significantly increased [5]. Due to higher radial forces, longer stents can be more prone to fracture than shorter ones. Stent fractures have also been observed with overlapping stents.

Because of the non-specific presentation of a stent fracture, it is a complication that can easily be missed. Patients may present with non-specific symptoms of angina which could be attributed to either stable or unstable angina as a result of restenosis or in-stent thrombosis, or both. In order to ensure proper recognition and treatment of this entity, physicians must be aware of its existence and the possibility of its occurrence under certain circumstances.

The incidence of these events could be underestimated because the widespread and slow tissue overgrowth inside the stent may mask the fracture. However, it is believed that not all stent fractures are associated with clinical sequelae so it is difficult to recognize them without repeat angiography. Stent thrombosis may result in death prior to hospitalization so it is possible that some cases of sudden death following DES implantation may result from unrecognized stent fracture.

This case demonstrates the most severe presentation of a BMS fracture, with sudden coronary thrombosis and subsequent myocardial infarction, which was diagnosed angiographically and treated early and effectively.

It is worth noting that the patient had no significant stent fracture predictors such as stent length (it was a relatively short stent), aggressive expansion and location (saphenous vein graft or right coronary artery).

This case describes one type of presentation of a stent fracture and how important it is to recognize a stent fracture, even if it is a rare occurrence. It is also important to note this in the management of patients who present with chest pain many years after percutaneous coronary intervention (PCI).

\section{Abbreviations}

ACS: acute coronary syndrome; BMS: bare-metal stent; DES: drug-eluting stent; LAD: left anterior descending artery; MB: muscle brain; MDCT: multidetector computed tomography; PCI: percutaneous coronary intervention.

\section{Competing interests}

The authors declare that they have no competing interests.

\section{Authors' contributions}

GM, PGP and CGa made substantial contributions in conceptualizing and designing this study. MSN and CGr performed the PCI. GM, HP and MS were involved in drafting 
the manuscript and revising it critically. All authors have given final approval of the version to be published.

\section{Consent}

Written consent was obtained from the patient for publication of this case report and any accompanying images. A copy of the written consent is available for review by the Editor-in-Chief of this journal.

\section{Additional material}

\section{Additional file 1}

Total occlusion of the LAD with complete fracture of mid portion of the stent.

Click here for file

[http://www.biomedcentral.com/content/supplementary/1752-

1947-3-9296-S1.MPG]

\section{Additional file 2}

Cypher stent $(3.0 \times 33 \mathrm{~mm})$ is superposed on the previous stent in the fractured occlusion area.

Click here for file

[http://www.biomedcentral.com/content/supplementary/1752-

1947-3-9296-S2.MPG]

\section{Additional file 3}

Cypher stent $(3.5 \times 8 \mathrm{~mm})$ in the proximal part is superposed on the previous stent in the fractured occlusion area.

Click here for file

[http://www.biomedcentral.com/content/supplementary/1752-

1947-3-9296-S3.MPG]

\section{Additional file 4}

Third stent, Cypher $(2.75 \times 28 \mathrm{~mm})$ in the mid-LAD is deployed. Click here for file

[http://www.biomedcentral.com/content/supplementary/17521947-3-9296-S4.MPG]

\section{Additional file 5}

Final angiogram showing successful reperfused culprit coronary artery.

Click here for file

[http://www.biomedcentral.com/content/supplementary/17521947-3-9296-S5.MPG]

\section{Acknowledgements}

We are grateful to the patient for his collaboration.

\section{References}

I. Lee SH, Park JS, Shin DG, Kim YJ, Hong GR, Kim W, Shim BS: Frequency of stent fracture as a cause of coronary restenosis after sirolimus-eluting stent implantation. Am J Cardiol 2007, 100(4):627-630.

2. Chowdhury PS, Ramos RG: Images in clinical medicine: coronary-stent fracture. N Engl J Med 2002, 347:58I.

3. Kwon SU, Doh JH, Namgung J, Lee SY: Images in cardiology: stent strut fracture-induced restenosis in the right coronary artery: detection by MDCT. Heart 2008, 94:22I.

4. Sacks BA, Miller A, Gottlieb M: Fracture of an iliac artery Palmaz stent. Vasc Interv Radiol 1996, 7(1):53-55.
5. Phipp LH, Scott DJ, Kessel D, Robertson I: Subclavian stents and stent-grafts: cause for concern? J Endovasc Surg 1999, 6(3):223-226.

6. Hamilos MI, Papafaklis MI, Ligthart JM, Serruys PW, Sianos G: Stent fracture and restenosis of a paclitaxel-eluting stent. Hellenic J Cardiol 2005, 46:439-442.

7. Sianos G, Hofma S, Ligthart JM, Saia F, Hoye A, Lemos PA, Serruys $\mathrm{PW}$ : Stent fracture and restenosis in the drug-eluting stent era. Catheter Cardiovasc Interv 2004, 6 I: I I I- I I6.

8. Min PK, Yoon YW, Moon Kwon H: Delayed strut fracture of sirolimus-eluting stent: a significant problem or an occasional observation? Int J Cardiol 2006, 106:404-406.

9. Jin X, Zhang S, Xie H, Wang C, Fan Z, Zeng Y, Shen Z, Fang Q: Strut fracture of DES: an increasing problem? Int J Cardiol 2007, I I 8:54-56.

10. Mitsutake R, Miura SI, Nishikawa H, Saku K: Usefulness of the evaluation of stent fracture by 64-multi-detector row computer tomography. J of Cardiol 2008, 52: | 35- I 38.
Publish with Bio Med Central and every scientist can read your work free of charge

"BioMed Central will be the most significant development for disseminating the results of biomedical research in our lifetime. "

Sir Paul Nurse, Cancer Research UK

Your research papers will be:

- available free of charge to the entire biomedical community

- peer reviewed and published immediately upon acceptance

- cited in PubMed and archived on PubMed Central

- yours - you keep the copyright
BioMedcentral 